\title{
Safety of First-line Chemotherapy with Metronomic Single-agent Oral Vinorelbine in Elderly Patients with NSCLC
}

\author{
MANLIO MENCOBONI ${ }^{1}$, ROSA ANGELA FILIBERTI ${ }^{2}$, PAOLA TAVEGGIA ${ }^{1}$, LISETTE DEL CORSO ${ }^{1}$, \\ ALESSANDRO DEL CONTE ${ }^{3}$, MARIA GRAZIA COVESNON ${ }^{4}$, CHETI PUCCETTI $^{5}$, SARA DONATI $^{5}$, \\ LAURA AURIATI ${ }^{6}$, DOMENICO AMOROSO ${ }^{5}$ and ANDREA CAMERINI ${ }^{5}$ \\ ${ }^{1}$ Oncology Unit, ${ }^{4}$ Pneumology Unit, ${ }^{6}$ Pathology Unit, Villa Scassi Hospital, Genoa, Italy; \\ ${ }^{2}$ Clinical Epidemiology, IRCCS AOU San Martino-IST-National Cancer Research Institute, Genoa, Italy; \\ ${ }^{3}$ Medical Oncology Unit, Santa Maria degli Angeli Hospital, Pordenone, Italy; \\ ${ }^{5}$ Medical Oncology, Versilia Hospital, Lido di Camaiore, Italy
}

\begin{abstract}
Background/Aim: The optimal therapeutic use of metronomic vinorelbine has not yet been defined. We aimed to assess the safety of metronomic oral vinorelbine in firstline treatment of elderly patients with advanced lung cancer who were unfit for polychemotherapy. Progression-free survival, response rate and overall survival were secondary end-points. Patients and Methods: Seventy-six patients received $50 \mathrm{mg}$ of oral vinorelbine three times per week, until disease progression, patient refusal or unacceptable toxicity. Patients were evaluated for response and toxicity after one cycle of chemotherapy. The treatment was considered feasible with a grade 3/4 toxicity rate lower than 20\%. Results: Clinical benefit was observed in 50\% of patients. Median overall survival was 8.0 months. Grade $1 / 2$ toxicity was observed in 53 patients (69.7\%), grade 3 toxicity in eight patients (10.5\%). One patient had grade 4 diarrhea. Conclusion: Metronomic oral vinorelbine is safe in elderly patients, allowing for long-term disease stabilization with optimal patient compliance.
\end{abstract}

About $40 \%$ of patients with advanced non-small cell lung cancers (NSCLC) are aged 70 years or older (1). The choice of the treatment for these patients is difficult: performance status, comorbidities, concomitant medications and organ failure are of concern for physicians. A recent meta-analysis demonstrated that an accurate geriatric assessment may reduce fatal toxicities by $20 \%$ (2). To date, three options are available for such patients: polychemotherapy, mono-

Correspondence to: Manlio Mencoboni, MD, Villa Scassi Hospital, Genoa-Italy. Mobile: +39 3387113418, Fax +39 0108630625, manlio.mencoboni@fastwebnet.it

Key Words: Non small cell lung cancer, vinorelbine, oral therapy, metronomic therapy, elderly. chemotherapy, and best supportive care. Polychemotherapy gives the best results, but toxicity may occur; monochemotherapy is better tolerated but results are not as good. Best supportive care is dedicated to those frail patients with performance status (PS) $>2$ or affected by severe organ failure, such as heart failure with New York Heart Association (NYHA) score $>2$ (3).

Originally formulated as an intravenous (i.v.) agent, vinorelbine is also currently available as an oral chemotherapeutic agent. Oral vinorelbine has demonstrated significant activity in different settings for NSCLC, including adjuvant treatment for resected disease, concurrent chemoradiation for locally advanced NSCLC, and palliative chemotherapy for recurrent/metastatic NSCLC (4). Vinorelbine was the first drug studied in mono-chemotherapy in elderly patients. The ELVIS study demonstrated statistically significant prolongation of survival in the elderly using a classical intravenous schedule (5). Oral vinorelbine has also been studied in the elderly with classical administration, with the same good outcomes (6). Toxicity was relevant, with neutropenia among $25-50 \%$.

Compared with i.v. chemotherapy, oral administration is convenient, requires fewer healthcare chemotherapy resources, is generally preferred by patients, and may be appropriate in older people with breast, colorectal or lung cancer. The effects of organ dysfunction on drug metabolism and drug interactions in patients with multiple comorbidities must be considered, but are not specific to oral chemotherapy. Many oncologists also have significant interest in metronomic chemotherapy $(7,8)$.

The concept of metronomic administration of chemotherapy has become relevant for the treatment of cancer in the past several years, especially in older patients. Metronomic chemotherapy refers to the administration of low doses of cytotoxic agents over a prolonged period of time with no or only short drug-free intervals. It is designed 
to overcome acquired tumor resistance to chemotherapy and to reduce neo-angiogenesis despite having a lower toxicity than standard chemotherapy. The role of metronomic chemotherapy, however, remains controversial, and its optimal therapeutic use has not yet been defined. Fifty milligrams given three times a week has been assessed as the optimal dose for metronomic oral vinorelbine in the treatment of NSCLC $(9,10)$.

The aim of this multicenter phase II pilot study was to assess the safety in terms of toxicity of metronomic oral vinorelbine in first-line treatment of elderly patients with advanced NSCLC unfit for polychemotherapy. Progressionfree survival (PFS), response rate (RR), and overall survival (OS) were secondary endpoints.

\section{Patients and Methods}

Eligible patients were male or female, $>70$ years of age unfit for polychemotherapy with cytohistologically confirmed NSCLC, metastatic (stage IV) or locally advanced (stage IIIB, with metastasis to supraclavear nodes or with pleural effusion) tumor and at least one target or non-target lesion. Patients had to be willing and able to take oral medication. Patients had to be newly diagnosed diagnosis or with recurrent disease after former surgery. Other eligibility criteria included Eastern Cooperative Oncology Group (ECOG) PS of 0-2, a life expectancy more than 3 months, and adequate hematological $\left(1.5 \times 10^{9} / 1\right.$ neutrophils, $100 \times 10^{9 / 1}$ platelets and $9 \mathrm{~g} / \mathrm{dl}$ hemoglobin), hepatic (bilirubin level either normal or $<1.5 \times$ upper limit of normal (ULN), aspartate transaminase (AST) and alanine transaminase (ALT) $\leq 2.5 \times$ ULN $(\leq 5 \times$ ULN if liver metastases present) and renal function (serum creatinine $<1.5 \times \mathrm{ULN}$ ). Patients with previous exposure to chemotherapy were excluded. We also excluded patients with any inflammatory changes of the surface of the eye at baseline or with unstable systemic disease (active infection, significant cardiovascular disease (NYHA $>3$ ), any significant hepatic, renal or metabolic disease), metabolically active dysfunction, other malignancies within 5 years (except for adequately treated carcinoma in situ of the cervix or basal or squamous cell skin cancer, or surgically resected prostate cancer with normal prostate-specific antigen), physical examination or clinical laboratory findings that contraindicated the use of study medications or rendered the patient at high risk from treatment complications. Patients with known or suspected hypersensitivity to any drug of the trial were also not eligible.

Patient evaluation included medical history, physical examination, ECOG PS determination and biochemistry (with carcino-embryonic antigen, cytokeratin 19 fragment, neuron-specific enolase at baseline and then every 21 days), complete blood cell count and serum chemistry (at baseline and then once a week). Serum chemistry includes ALT, AST, $\gamma$-glutamyl transferase, alkaline phosphatase, total bilirubin, $\mathrm{Na}, \mathrm{K}, \mathrm{Ca}, \mathrm{P}, \mathrm{Mg}$, creatinin, uric acid. In addition, patients underwent computed tomography (total body and brain scan, at baseline and every 42 days) and bone scan (at baseline and every 6 months) if indicated.

Treatment. Patients received oral vinorelbine (Pierre Fabre Pharma) at the dose of $50 \mathrm{mg}$ three times per week (on Monday, Wednesday, Friday), until disease progression, patient refusal or unacceptable
Table I. Characteristics of vinorelbine-treated patients of this study.

\begin{tabular}{|c|c|c|}
\hline & No. of patients $(\mathrm{N}=76)$ & $\%$ \\
\hline \multicolumn{3}{|l|}{ Gender } \\
\hline Male & 61 & 80.3 \\
\hline Female & 15 & 19.7 \\
\hline Age, median (range), years & $79.0(70-92)$ & \\
\hline \multicolumn{3}{|l|}{ Histology } \\
\hline Adenocarcinoma & 31 & 40.8 \\
\hline Squamous & 35 & 46.1 \\
\hline Anaplastic large cell carcinoma & 4 & 5.3 \\
\hline NSCLC unspecified & 6 & 7.9 \\
\hline \multicolumn{3}{|l|}{ Stage } \\
\hline III & 29 & 38.2 \\
\hline IV & 47 & 61.8 \\
\hline \multicolumn{3}{|l|}{ ECOG PS } \\
\hline 0 & 20 & 26.3 \\
\hline 1 & 25 & 32.9 \\
\hline 2 & 31 & 40.8 \\
\hline \multicolumn{3}{|l|}{ Smoking status } \\
\hline Never smoker & 7 & 9.2 \\
\hline Smoker & 69 & 90.8 \\
\hline \multicolumn{3}{|l|}{ Number of comorbidities } \\
\hline$\leq 1$ & 27 & 35.5 \\
\hline $2-3$ & 33 & 43.4 \\
\hline$\geq 4$ & 16 & 21.1 \\
\hline
\end{tabular}

NSCLC: Non-small cell lung cancer; ECOG PS: Eastern Cooperative Oncology Group performance status.

toxicity. Vinorelbine doses were administered at home immediately after a light lunch. Conventionally, 3 weeks of therapy were considered as one cycle.

Prophylactic anti-nauseants were allowed. Antibiotics or granulocyte colony-stimulating factors or erythropoietin were not allowed prophylactically, but were allowed in the case of toxicity.

Patients were evaluated for response by computed tomographic scan every 6 weeks according to the Response Evaluation Criteria in Solid Tumors (RECIST) (11).

Safety. All patients who received at least one cycle of chemotherapy (21 days) were evaluable for toxicity.

All clinical adverse events (AEs) encountered during the clinical study were reported. Intensity of events was assessed according to the current NCI Common Terminology Criteria for Adverse Events (CTC-AE version 4.0) on a five-point scale (grade 1 to 5) (12). In the case of grade 3-4 toxicity, treatment was stopped for 7 days and therapies were administered according to good clinical practice. If after 7 days toxicity had gone, treatment started again at the dose of $40 \mathrm{mg}$ three times a week. Definition of unacceptable toxicity was grade 4 febrile neutropenia, thrombocytopenia and nonhematological toxicity except alopecia present after 7 days of suspension of treatment or a second grade 3/4 toxicity. Treatment was continued until disease progression or the presence of unacceptable toxicity.

The study was approved by the Ethical Committee of the participating centers and was conducted according to the Helsinki Declaration. All patients provided written informed consent to participate. 
Table II. Toxicity in vinorelbine-treated patients of this study*.

\begin{tabular}{|c|c|c|c|c|c|}
\hline \multirow[b]{2}{*}{ Toxicity } & \multicolumn{4}{|c|}{ Grade, n (\%) } & \multirow[b]{2}{*}{ Total, n (\%) } \\
\hline & 1 & 2 & 3 & 4 & \\
\hline \multicolumn{6}{|l|}{ Hematological } \\
\hline Anemia & $14(60.9 \%)$ & $8(34.8 \%)$ & $1(4.3 \%)$ & & $23(30.3 \%)$ \\
\hline Leukopenia & & & $1(100 \%)$ & & $1(1.3 \%)$ \\
\hline Neutropenia & $3(100 \%)$ & & & & $3(3.9 \%)$ \\
\hline Thrombocytopenia & $2(100 \%)$ & & & & $2(2.6 \%)$ \\
\hline \multicolumn{6}{|l|}{ Non-hematological } \\
\hline Asthenia & $4(14.3 \%)$ & $22(78.6 \%)$ & $2(7.1 \%)$ & & $28(36.8 \%)$ \\
\hline Dyspepsia & $2(100 \%)$ & & & & $2(2.6 \%)$ \\
\hline Nausea & $9(56.2 \%)$ & $6(37.5 \%)$ & $1(6.2 \%)$ & & $16(21.0 \%)$ \\
\hline Vomiting & $6(85.7 \%)$ & $1(14.3 \%)$ & & & $7(9.2 \%)$ \\
\hline Diarrhea & $5(41.7 \%)$ & $5(41.7 \%)$ & $1(8.3 \%)$ & $1(8.3 \%)$ & $12(15.8 \%)$ \\
\hline Constipation & $7(87.5 \%)$ & $1(12.5 \%)$ & & & $8(10.5 \%)$ \\
\hline Candidiasis & $1(100 \%)$ & & & & $1(1.3 \%)$ \\
\hline Mucositis & $1(33.3 \%)$ & $1(33.3 \%)$ & $1(33.3 \%)$ & & $3(3.9 \%)$ \\
\hline Bronchial infection & & $1(100 \%)$ & & & $1(1.3 \%)$ \\
\hline Hemoptysis & $1(100 \%)$ & & & & $1(1.3 \%)$ \\
\hline Neurotoxicity & $1(100 \%)$ & & & & $1(1.3 \%)$ \\
\hline Paresthesia & $3(100 \%)$ & & & & $3(3.9 \%)$ \\
\hline Fatigue & $2(50 \%)$ & $2(50 \%)$ & & & $4(5.3 \%)$ \\
\hline Hyporexia & $1(50 \%)$ & & $1(50 \%)$ & & $2(2.6 \%)$ \\
\hline
\end{tabular}

*Some patients had more than one toxicity.

Statistical analysis. Based on data from clinical trials and in daily clinical practice, an initial sample size of 80 patients was calculated in order to have $70 \%$ power to achieve a toxicity lower than $20 \%$.

The distribution of continuous variables are reported as the median (range). The study population was categorized according to the median of the age distribution ( $\leq 79$ and $>79$ years), stage (III and IV), ECOG PS (0-1 and 2), and smoking status as never smoker and smoker (former- and current smoker). For categorical variables, frequencies and proportions are reported and the relationship between variables was examined by means of the chi-square test. The Kaplan-Meier method was applied in univariate analysis to estimate PFS and OS probabilities and the log-rank test was carried out to assess heterogeneity within each prognostic factor. PFS was defined as the time from vinorelbine initiation until documented disease progression or last follow-up. OS was defined as the time from treatment initiation until death from any cause or last followup. Confidence intervals (CIs) were calculated at the 95\% level. Statistical calculations were performed using the SPSS statistical package version 20 (IBM Corp., Armonk, NY, USA).

\section{Results}

Seventy-six patients were enrolled from June 2011 to May 2014. Patient characteristics at enrollment were as follows: median age 79 years (range $=70-92$ years), 61 were males, histological subtype was squamous carcinoma in 35, and 47 patients had stage IV disease. Sixty-nine patients (90.8\%) were smokers (Table I). ECOG PS was 1 or 2 in 56 patients
$(73.7 \%)$. Patients had a median of 2 (range=0-7) serious comorbidities, the most reported being chronic obstructive pulmonary disease (34\%), cardiovascular disease (42\%), hypertension $(53 \%)$, and diabetes $(24 \%)$.

Patients received a median of 4 cycles (range $=1-21$ ) of therapy: $47.4 \%(36 / 76)$ received at least 5 cycles and $13.2 \%$ received at least 10 cycles.

Drug administration and toxicity. Thirty-one patients were treated in second-line: 17 with erlotinib, seven with gemcitabine, four with taxotere and three with carboplatin and one of them received a third-line treatment. There was no treatment-related death or hospitalization for treatmentrelated adverse events. No patient required blood or platelet transfusions or intravenous antibiotics.

Overall, toxicity was observed in 54 patients $(71.1 \%)$ for a total of 423 cycles of treatment. Some patients had more than one toxicity. Grade $1 / 2$ toxicity was observed in 53 patients $(69.7 \%)$, with prevalence of asthenia (34.2\%), anemia $(28.9 \%)$, nausea $(19.7 \%)$ and diarrhea $(13.2 \%)$. Grade 3 toxicity was observed in eight out of these 53 patients $(10.5 \%$ out of all patients: asthenia $(n=2)$, anemia, leukopenia, nausea, diarrhea, hyporexia, or mucositis). One of these patient also had grade 4 toxicity (diarrhea) (Table II). The patients with grade 3 and 4 toxicity had dose delay and one-step dose reduction to $40 \mathrm{mg}$ three times weekly. 
Response to therapy, PFS and OS. Eleven patients (14.5\%) achieved a partial response, while disease stability was observed in 27 patients $(35.5 \%)$, providing clinical benefit to $50 \%$ of patients. Progressive disease was reported in $44.7 \%$ Responders were more likely to be male (81.6\%) and with good PS $(63.2 \%)$, but no significant association was found between response and individual or clinical variables (data not shown). At the end of follow-up, 74 patients $(97.4 \%)$ experienced disease progression. Overall, the median PFS was 3.0 months (95\% CI=2.6-3.5 months). No significant differences were observed for PFS with regard to age ( $\leq 79$ vs. 79 years), gender, histology, stage or PS.

During the study period, 74 patients $(97.4 \%)$ died. For the whole group, the median duration of survival was 8.0 months (95\% CI=6.6-9.4 months). The 6- and 12-months OS rates were $30 \%$ and $20 \%$, respectively. Survival of patients according to the various prognostic factors is shown in Table III. Patients with stable disease or response as best response survived a median of 12 months compared to 5.0 months for those with disease progression $(p<0.001)$.

\section{Discussion}

In the present study, we evaluated the safety and outcome of 76 elderly patients with advanced/metastatic NSCLC undergoing a metronomic schedule of oral vinorelbine at a dose of $50 \mathrm{mg}$ three times a week until progression or toxicity. Safety was measured in terms of inacceptable toxicity (grade $3 / 4$ ). The primary endpoint (grade $3 / 4$ toxicity lower than $20 \%$ ) was reached. In fact, grade 3 toxicity occurred in $10.5 \%$ of patients and only one of these had a concomitant grade 4 toxicity. Clinical benefit was achieved in $50 \%$ of patients and $20 \%$ of patients were still alive at 1 year.

Single-agent chemotherapy is an appropriate option for treating elderly patients with advanced NSCLC or those with low PS $(10,13,14)$. Vinorelbine is a semi-synthetic vincaalkaloid with significant antitumor activity against a variety of cancer types. It represents an effective option for NSCLC in the adjuvant setting and in the treatment of advanced disease. The drug exerts its cytotoxicity via inhibition of microtubule assembly and is used in several regimens to treat patients with metastatic breast cancer or NSCLC, being effective as monotherapy in unfit elderly patients with advanced tumors unsuitable for combination regimens and in previously treated patients (15).

Metronomic administration of cytotoxic drugs with a frequent administration of low doses over long periods of time reduces their toxic effects compared to administration of the maximum-tolerated dose. The goal of metronomic chemotherapy is to overcome tumor resistance through continuous drug exposure, with limited toxicity due to the low doses used, and to inhibit endothelial cell proliferation, thereby optimizing the antiangiogenic effects of therapy (4,
Table III. Overall survival according to individual characteristics in vinorelbine-treated patients of this study.

\begin{tabular}{|c|c|c|c|c|}
\hline & $\mathrm{N}$ & $\begin{array}{l}\text { Median } \\
\text { survival } \\
\text { (months) }\end{array}$ & $95 \% \mathrm{CI}$ & $p$-Value \\
\hline Overall & 76 & 8.0 & $6.6-9.4$ & \\
\hline Age & & & & 0.5 \\
\hline$\leq 79$ Years & 39 & 7.1 & 4.1-10.2 & \\
\hline$>79$ Years & 37 & 9.0 & 7.6-10.4 & \\
\hline Gender & & & & 0.7 \\
\hline Male & 61 & 9.0 & 7.6-10.4 & \\
\hline Female & 15 & 7.5 & $0.3-14.7$ & \\
\hline Histology & & & & 0.4 \\
\hline Adenocarcinoma & 31 & 7.8 & $6.0-9.6$ & \\
\hline Squamous cell carcinoma & 35 & 9.0 & $6.2-11.8$ & \\
\hline Anaplastic large cell carcinoma & 4 & 90 & $0.2-17.8$ & \\
\hline NSCLC unspecified & 6 & 5.0 & $3.8-6.2$ & \\
\hline Stage & & & & 0.067 \\
\hline III & 29 & 9.0 & $6.1-11.9$ & \\
\hline IV & 47 & 7.8 & $6.3-9.2$ & \\
\hline ECOG PS & & & & 0.094 \\
\hline $0-1$ & 45 & 9.3 & $6.2-12.4$ & \\
\hline$\geq 2$ & 31 & 7.2 & $5.0-9.4$ & \\
\hline Best response & & & & $<0.001$ \\
\hline Progression & 34 & 5.0 & $4.1-5.9$ & \\
\hline Stable disease/response & 38 & 12.0 & $4.1-5.9$ & \\
\hline
\end{tabular}

NSCLC: Non-small cell lung cancer; ECOG PS: Eastern Cooperative Oncology Group performance status.

16-18). Oral formulation of vinorelbine appears to be similar to that of the intravenous agent with regard both to activity and safety, and has allowed the possibility of optimal metronomic scheduling (19-22). This formulation has been shown to have good antitumor activity and low toxicity and is considered advantageous for metronomic scheduling in terms of ease of administration, cost-saving in relation to hospital expenses, drug preparation and infusion-related procedures $(21,23)$. Oral vinorelbine is rapidly absorbed after ingestion and is not affected by concomitant food intake or by vomiting occurring $1.5 \mathrm{~h}$ or later after dosing. Bioavailability ranges from 33 to $43 \%$ and the drug has a terminal half-life of approximately $29 \mathrm{~h}$, permitting thrice weekly or every other day dosing. No significant differences in the pharmacokinetics of oral vinorelbine were observed between elderly and younger patients $(21,24,25)$.

A cumulative weekly oral dose of $150 \mathrm{mg}$ is equivalent to a weekly parenteral dose of $65 \mathrm{mg}$, or about $38 \mathrm{mg} / \mathrm{m}^{2}$ for an individual of average size. Therefore, oral thrice weekly delivery results in delivery comparable to weekly parenteral dosing, but produces more protracted exposure to lower drug concentrations (21). Furthermore, patients prefer and are less concerned about the oral formulation with respect to i.v. access (26). In patients with lung cancer, the use of oral 
vinorelbine as an alternative to i.v. administration can prevent thoracic pain, probably due to a lower peak of blood concentration of the drug (27).

A crucial point is to identify the right metronomic scheduling in order to achieve better efficacy and acceptable toxicity levels. It has been shown that a dose and schedule of $50 \mathrm{mg}$ thrice weekly administered for at least 3 consecutive weeks or longer is feasible, with both acceptable toxicity and antineoplastic activity $(9,21,23,28)$. To the best of our knowledge, only few studies are available on the use of metronomic vinorelbine in patients with lung cancer $(10,29-31)$, and only few of them reported on the use of the therapy as monotherapy (32).

The most important (grade 3 or 4 ) adverse events effects occurring with oral vinorelbine monotherapy in another study on elderly patients with advanced NSCLC were hematological: neutropenia (50\%), leucopenia (39\%), anemia (4\%), and febrile neutropenia (2\%). Among non-hematological toxicity, grade 3 fatigue $(11 \%)$; nausea (54\%), mostly grades 1 and $2(50 \%)$; vomiting (21\% grade $1-2$ and $4 \%$ grade 3$)$; diarrhea $(33 \%$ grade $1-2$ and $5 \%$ grade 3 ); and constipation (23\% grade $1-2$ and $2 \%$ grade 3 ) were reported. In addition, grade 1-2 neurosensory symptoms were reported in $5 \%$ of patients. There were no relevant hepatic or renal effects. Disease control was obtained in $66 \%$ of patients, with a PFS and a median OS of 3.7 and 8.2 months, respectively (6).

Metronomic scheduling of vinorelbine plus cisplatin in patients with different types of tumors resulted in grade 3 or 4 neutropenia in $27 \%$ to $31 \%$, febrile neutropenia in $8 \%$ and fatigue in $11 \%$ of patients. Disease control was achieved in about $64 \%$ of patients $(30,31)$. In other studies, metronomic oral vinorelbine monotherapy seemed well-tolerated, with grade 3-4 neutropenia in $0.1-24 \%$ of patients, febrile neutropenia in $11 \%$, fatigue in $0.1-11 \%$. Non-hematological toxicities such as nausea, vomiting, abdominal or epigastric pain, mucositis, anorexia, diarrhea or constipation were mild. Disease control was achieved in $31-58 \%$, with a median PFS and OS of 2.2-5 and 9.4 months, respectively $(9,10,28,32)$.

Our results met the default clinical interest threshold (toxicity lower than $20 \%$ of patients) and confirmed that single-agent metronomic oral vinorelbine therapy has an acceptable clinical efficacy and safety. These data are valuable, especially in a population of elderly patients with advanced NSCLC unfit for polychemotherapy, but still suitable for active treatment. The median age of our population was very high and many comorbidities were present. Hence, our results highlight the safety of metronomic therapy and indicate that oral metronomic vinorelbine may be a treatment option in elderly patients. Activity is not the primary endpoint of this work, which was not powered to assess this in a conclusive way, however, activity did not seem inferior with respect to other chemotherapy regimens that may be not feasible in such a population.
In conclusion, metronomic oral vinorelbine is safe in elderly patients with advanced NSCLC, allowing longterm disease stabilization together with optimal patient compliance.

\section{Acknowledgements}

The Authors are grateful to Elisabetta Ginocchio for editing the manuscript, and to Antonella La Camera, Antonio Messina and Ornella Gallone for data management.

\section{References}

1 Weir HK, Thun MJ, Hankey BF, Ries LA, Howe HL, Wingo PA, Jemal A, Ward E, Anderson RN and Edwards BK: Annual report to the nation on the status of cancer, 1975-2000. featuring the use of surveillance data for cancer prevention and control. J Natl Cancer Inst 95: 1276-1299, 2003.

2 NSCLC Meta-Analyses Collaborative Group: Chemotherapy in addition to supportive care improves survival in advanced nonsmall-cell lung cancer: a systematic review and metaanalysis of individual patient data from 16 randomized controlled trials. J Clin Oncol 26: 4617-4625, 2008.

3 De Marinis F, Bria E, Baas P, Tiseo M, Camerini A, Favaretto AG and Gridelli C: Treatment of Unfit Patients With Advanced Non-Small-Cell Lung Cancer: Definition Criteria According an Expert Panel. Clin Lung Cancer 16: 399-405, 2015.

4 Barletta G, Genova C, Rijavec E, Burrafato G, Biello F, Sini C, Dal Bello MG, Coco S, Truini A, Vanni I, Alama A, Beltramini S, Grassi MA, Boccardo F and Grossi F: Oral vinorelbine in the treatment of non-small-cell lung cancer. Expert Opin Pharmacother 15: 1585-1599, 2014.

5 Elderly Lung Cancer vinorelbine Italian Study (ELVIS) Group: Effects of vinorelbine on quality of life and survival of elderly patients with advanced non-small cell lung cancer. J Natl Cancer Inst 91: 66-72, 1999.

6 Gridelli C, Manegold C, Mali P, Reck M, Portalone L, Castelnau O, Stahel R, Betticher D, Pless M, Pons JT, Aubert D, Burillon JP, Parlier Y and De Marinis F: Oral vinorelbine given as monotherapy to advanced, elderly NSCLC patients: a multicentre phase II trial. Eur J Cancer 40: 2424-2431, 2004.

7 Biganzoli L, Lichtman S, Michel JP, Papamichael D, Quoix E, Walko C and Aapro M: Oral single-agent chemotherapy in older patients with solid tumours: A position paper from the International Society of Geriatric Oncology (SIOG). Eur J Cancer 51: 2491-2500, 2015.

8 Collovà E, Sebastiani F, De Matteis E, Generali D, Aurilio G, Boccardo F, Crispino S and Cruciani G: Use of metronomic chemotherapy in oncology: results from a National Italian survey. Tumori 97: 454-458, 2011.

9 Briasoulis E, Aravantinos G, Kouvatseas G, Pappas P, Biziota E, Sainis I, Makatsoris T, Varthalitis I, Xanthakis I, Vassias A, Klouvas G, Boukovinas I, Fountzilas G, Syrigos KN, Kalofonos $\mathrm{H}$ and Samantas E: Dose selection trial of metronomic oral vinorelbine monotherapy in patients with metastatic cancer: a hellenic cooperative oncology group clinical translational study. BMC Cancer 13: 263, 2013. 
10 Camerini A, Puccetti C, Donati S, Valsuani C, Petrella MC, Tartarelli G, Puccinelli P and Amoroso D: Metronomic oral vinorelbine as first-line treatment in elderly patients with advanced non-small cell lung cancer: results of a phase II trial (MOVE trial). BMC Cancer 15: 359, 2015.

11 Eisenhauer EA, Therasse P, Bogaerts J, Schwartz LH, Sargent D, Ford R, Dancey J, Arbuck S, Gwyther S, Mooney M, Rubinstein L, Shankar L, Dodd L, Kaplan R, Lacombe D and Verweij J: New response evaluation criteria in solid tumours: revised RECIST guideline (version 1.1). Eur J Cancer 45: 228247,2009

12 National Institutes of Health and National Cancer Institute. Common Terminology Criteria for Adverse Events (CTCAE) Version 4.0. U.S. Department of Health and Human Sciences; National Institutes of Health and National Cancer Institute; 2009.

13 Peters S, Adjei AA, Gridelli C, Reck M, Kerr K, Felip E; ESMO Guidelines Working Group: Metastatic non-small-cell lung cancer (NSCLC): ESMO Clinical Practice Guidelines for diagnosis, treatment and follow-up. Ann Oncol 23(Suppl 7): vii56-64, 2012.

14 Meoni G, Cecere FL, Lucherini E and Di Costanzo F: Medical treatment of advanced non-small cell lung cancer in elderly patients: a review of the role of chemotherapy and targeted agents. J Geriatr Oncol 4: 282-290, 2013.

15 Goa KL and Faulds D: vinorelbine. A review of its pharmacological properties and clinical use in cancer chemotherapy. Drugs Aging 5: 200-234, 1994.

16 Kerbel RS and Kamen BA: The anti-angiogenic basis of metronomic chemotherapy. Nat Rev Cancer 4: 423-436, 2004.

17 Hanahan D, Bergers G and Bergsland E: Less is more, regularly: metronomic dosing of cytotoxic drugs can target tumor angiogenesis in mice. J Clin Invest 105: 1045-1047, 2000.

18 Colleoni M, Orlando L, Sanna G, Rocca A, Maisonneuve P, Peruzzotti G, Ghisini R, Sandri MT, Zorzino L, Nolè F, Viale G and Goldhirsch A: Metronomic low-dose oral cyclophosphamide and methotrexate plus or minus thalidomide in metastatic breast cancer: antitumor activity and biological effects. Ann Oncol 17: 232-238, 2006

19 Gridelli C, Perrone F, Gallo C, Cigolari S, Rossi A, Piantedosi F, Barbera S, Ferraù F, Piazza E, Rosetti F, Clerici M, Bertetto O, Robbiati SF, Frontini L, Sacco C, Castiglione F, Favaretto A, Novello S, Migliorino MR, Gasparini G, Galetta D, Iaffaioli RV, Gebbia V; MILES Investigators: Chemotherapy for elderly patients with advanced non-small-cell lung cancer: the Multicenter Italian Lung Cancer in the Elderly Study (MILES) phase III randomized trial. J Natl Cancer Inst 95: 362-372, 2003.

20 The Elderly Lung Cancer vinorelbine Italian Study group: Effects of vinorelbine on quality of life and survival of elderly patients with advanced non-small cell lung cancer. J Natl Cancer Inst 85: 365-376, 1999.

21 Barbolosi D, Ciccolini J, Meille C, Elharrar X, Faivre C, Lacarelle B, André $\mathrm{N}$ and Barlesi F: Metronomics chemotherapy: time for computational decision support. Cancer Chemother Pharmacol 74: 647-652, 2014.

22 Gralla RJ, Gatzemeier U, Gebbia V, Huber R, O'Brien M and Puozzo C: Oral vinorelbine in the treatment of non-small cell lung cancer: rationale and implications for patient management. Drugs 67: 1403-1410, 2007.
23 Briasoulis E, Pappas P, Puozzo C, Tolis C, Fountzilas G, Dafni $\mathrm{U}$, Marselos $\mathrm{M}$ and Pavlidis N: Dose-ranging study of metronomic oral vinorelbine in patients with advanced refractory cancer. Clin Cancer Res 15: 6454-6461, 2009.

24 Rowinsky EK, Noe DA, Trump DL, Winer EP, Lucas VS, Wargin WA, Hohneker JA, Lubejko B, Sartorius SE and Ettinger DS: Pharmacokinetic, bioavailability, and feasibility study of oral vinorelbine in patients with solid tumors. J Clin Oncol 12: 17541763, 1994.

25 Depierre A, Freyer G, Jassem J, Orfeuvre H, Ramlau R, Lemarie E, Koralewski P, Mauriac L, Breton JL, Delozier T and TrilletLenoir V: Oral vinorelbine: feasibility and safety profile. Ann Oncol 12: 1677-1681, 2001.

26 Jensen LH, Osterlind K and Rytter C: Randomized cross-over study of patient preference for oral or intravenous vinorelbine in combination with carboplatin in the treatment of advanced NSCLC. Lung Cancer 62: 85-91, 2008.

27 De Pas T, Sbanotto A, Catania C, Banfi MG, Curigliano G, Nolè F, Fazio N, Formica V, Veronesi G and de Braud F: Oral administration of vinorelbine can overcome intractable endovenous-vinorelbine-associated acute tumor pain. Support Care Cancer 13: 194-195, 2005.

28 Rajdev L, Negassa A, Dai Q, Goldberg G, Miller K and Sparano JA: Phase I trial of metronomic oral vinorelbine in patients with advanced cancer. Cancer Chemother Pharmacol 68: 1119-1124, 2011.

29 Tan EH, Tan DS, Li WY, Haaland B, Ang MK, Chau NM, Toh CK, Tan IB, Koh TS, Thng CH, Chowbay B, Hui KM, Lim WT and $\mathrm{Ng}$ QS: Metronomic vinorelbine (oral) in combination with sorafenib in advanced non-small cell lung cancer. Lung Cancer 88: 289-296, 2015.

30 Katsaounis P, Kotsakis A, Agelaki S, Kontopodis E, Agelidou A, Kentepozidis N, Vamvakas L, Christopoulou A, Karachaliou N, Hatzidaki D and Georgoulias V: Cisplatin in combination with metronomic vinorelbine as front-line treatment in advanced nonsmall cell lung cancer: a multicenter phase II study of the Hellenic Oncology Research Group (HORG). Cancer Chemother Pharmacol 75: 821-827, 2015.

31 Pallis AG, Chandrinos V, Pavlakou G, Xenidis N, Varthalitis I, Vardakis N, Vamvakas L, Kontopodis E, Rovithi M and Georgoulias V: A multicenter phase I trial of metronomic oral vinorelbine plus cisplatin in patients with NSCLC. Cancer Chemother Pharmacol 67: 1239-1245, 2011.

32 Kontopodis E, Hatzidaki D, Varthalitis I, Kentepozidis N, Giassas S, Pantazopoulos N, Vardakis N, Rovithi M, Georgoulias V and Agelaki S: A phase II study of metronomic oral vinorelbine administered in the second line and beyond in non-small cell lung cancer (NSCLC): a phase II study of the Hellenic Oncology Research Group. J Chemother 25: 49-55, 2013.

Received March 28, 2017

Revised April 13, 2017

Accepted April 19, 2017 